\title{
Adoption and use of guidelines for whiplash: an audit of insurer and health professional practice in New South Wales, Australia
}

Aila Nica Bandong ${ }^{1,2,6^{*}}$ (D), Andrew Leaver ${ }^{1}$, Martin Mackey ${ }^{1}$, Rodney Ingram ${ }^{1}$, Samantha Shearman ${ }^{1}$, Christen Chan', Ian D Cameron ${ }^{3}$, Niamh Moloney ${ }^{4}$, Rebecca Mitchell ${ }^{5}$, Eoin Doyle ${ }^{4}$, Emma Leyten ${ }^{4}$ and Trudy Rebbeck ${ }^{1,3}$

\begin{abstract}
Background: In Australia, the New South Wales (NSW) State Insurance Regulatory Authority has been continuously developing and implementing clinical practice guidelines to address the health and economic burden from whiplash associated disorders (WAD). Despite this, it is uncertain the extent to which the guidelines are followed. This study aimed to determine insurer and health professional compliance with recommendations of the 2014 NSW clinical practice guidelines for the management of acute WAD; and explore factors related to adherence.

Methods: This was an observational study involving an audit of 288 randomly-selected claimant files from 4 insurance providers in NSW, Australia between March and October 2016. Data extracted included demographic, claim and injury details, use of health services, and insurer and health professional practices related to the guidelines. Analyses involved descriptive statistics and correlation analysis.

Results: Median time for general practitioner medical consultation was 4 days post-injury and 25 days for physical treatment (e.g. physiotherapy). Rates of $x$-ray investigations were low (21.5\%) and most patients (90\%) were given active treatments in line with the guideline recommendations. The frequency of other practices recommended by the guidelines suggested lower guideline adherence in some areas such as; using the Quebec Task Force classification (19. 9\%); not using specialised imaging for WAD grades I and II (e.g. MRI, 45.8\%); not using routine passive treatments (e.g. manual therapy, 94.0\%); and assessing risk of non-recovery using relevant prognostic tools (e.g. Neck Disability Index, 12.8\%). Over half of the claimants (59.0\%) were referred to other professionals at 9-12 weeks post-injury, among which $31.2 \%$ were to psychologists and $68.8 \%$ to specialists (surgical specialists, 43.6\%; WAD specialists, 20.5\%). Legal representation and lodgment of full claim were associated with increased number of medical visits and imaging ( $\rho$ o. 23 to $0.3 ; p<0.01$.

Conclusion: There is evidence of positive uptake of some guideline recommendations by insurers and health professionals; however, there are practices that are not compliant and might lead to poor health outcomes and greater treatment cost. Organisational, regulatory and professional implementation strategies may be considered to change practice, improve scheme performance and ultimately improve outcomes for people with WAD.
\end{abstract}

Keywords: Guideline adherence, Professional practice, Insurance audits, Whiplash injury, Compliance, Clinical practice guidelines, Primary care

\footnotetext{
* Correspondence: aban9213@uni.sydney.edu.au

${ }^{1}$ Faculty of Health Sciences, The University of Sydney, 75 East Street, Sydney,

Australia

${ }^{2}$ College of Allied Medical Professions, University of the Philippines, Manila,

Philippines

Full list of author information is available at the end of the article
}

(c) The Author(s). 2018 Open Access This article is distributed under the terms of the Creative Commons Attribution 4.0 International License (http://creativecommons.org/licenses/by/4.0/), which permits unrestricted use, distribution, and reproduction in any medium, provided you give appropriate credit to the original author(s) and the source, provide a link to the Creative Commons license, and indicate if changes were made. The Creative Commons Public Domain Dedication waiver (http://creativecommons.org/publicdomain/zero/1.0/) applies to the data made available in this article, unless otherwise stated. 


\section{Background}

In primary musculoskeletal health care, many elements of practice have been identified as being ineffective and costly. Such practices include overuse of imaging and overuse of passive interventions [1-5]. Accordingly, clinical practice guidelines have been developed and implemented to promote an evidence-based approach to patient care. These guidelines advocate a biopsychosocial approach with emphasis on secondary prevention of disability and promotion of self-management [6]. Recommendations therefore include; diagnosis based on triage, limited and targeted use of imaging, provision of active (performed by the patient requiring volitional effort) rather than passive (performed by a therapist with no patient effort) treatments, defined timeframes for review for an episode of care and appropriate referral of people who are not recovering. However, guideline implementation and changing professional practice remain a challenge in health care [7-9]. Prior research has shown that implementation strategies had variable effects in changing practice and where effective, these strategies appeared to influence only a few elements of practice [10-15]. Further, effectiveness of these strategies has been evaluated between 3 to 12 months after the intervention and long-term practice change has not been assessed. This is important because sustaining change in practice ensures quality care through continued provision of best treatments and efficient use of allocated resources [16-18].

Implementation strategies for musculoskeletal guidelines have shown positive effects on practices such as referral for imaging and provision of active treatments. Requests for $\mathrm{x}$-rays have reduced with strategies such as distribution of educational materials, educational meetings and reminder messages [19-24]. .Health professionals more frequently advised active treatments in the management of neck pain and low back pain after delivery of a multi-faceted strategy involving educational meetings [13]. Further, the number and duration of physiotherapy visits decreased after a continuing education course and subsequent educational meetings on evidence-based management for neck pain were implemented [25]. Similarly, in arthritis management, improvements in provision of education, joint protection, social support, weight management, onward referral and prescription of medication have been observed [26].

In New South Wales (NSW) Australia, clinical practice guidelines for whiplash associated disorders (WAD) have been developed, updated and implemented over the past 17 years by the state insurance regulator, State Insurance Regulatory Authority (SIRA) [27-29]. WAD is a huge health and economic burden in Australia with $50 \%$ of people with WAD experiencing persisting pain and disability [30]. Annual costs for WAD are more than $\$ 950$ million [31] and in NSW, 46\% of all claims lodged since 2007 were attributed predominantly to WAD [29]. The WAD guidelines assist health professionals to deliver best care and insurers in their decision about funding best care [27-29]. The key guideline messages about assessment, interventions, prognosis, review and referral have been consistent through all iterations of the guidelines [27-29]. The WAD guidelines have been disseminated since their inception with an extensive and strategic implementation program. This program has included dissemination through professional associations $[32,33]$, educational workshops in insurance companies [34], education by opinion leaders [35, 36] and online education [37].

Consistent with results of studies in other musculoskeletal conditions, implementation strategies for WAD guidelines to date have resulted to varying success in changing professional practice of insurers and health professionals. Awareness of and compliance with the guidelines have increased among insurance staff and health professionals have improved provision of active treatments, reassurance and classification of WAD following an educational session led by opinion leaders [34-37]. However, there was no change demonstrated on use of appropriate outcome measures and identification of poor prognosis [36]. Compliance with recommendations on use of imaging, passive interventions and providing associated clinical care pathways have also not been explored. These elements of practice have therefore been targeted in the implementation of the most recent version of the WAD clinical practice guidelines released in 2014 [29].

Full implementation of guidelines typically takes 3 years [9] and the WAD guidelines have been actively implemented since 1999. It is therefore timely to ascertain whether insurers and health professionals continue to provide guideline-based care to people with WAD. One method to evaluate compliance with guidelines is through an audit of practice. Audit of practice has been utilised in previous studies to measure professional practice change [21, 35, 36, 38-40], with this method argued as one of the more robust methods to evaluate quality of the process care $[41,42]$. Process of care data involve aspects of the health professional-patient encounter and can be obtained from various sources including clinical notes, patient forms and insurer records [43]. Audit of insurer approvals and disapprovals and the timing of these decisions can also provide insight into indicators of scheme performance.

In NSW Australia, submission of claim-related documentation such as claim forms (e.g. accident notification form (ANF), personal injury claim form (PICF)) and physical treatment request forms (notification of commencement (NOC) form, review form) are the primary 
mechanisms for communicating details of management to insurers and accessing treatments after WAD. A systematic evaluation of claim-related documentation provides a picture of the extent to which insurers and health professionals are implementing the WAD guidelines. An audit of claim-related documentation will also allow for exploration of other factors that could influence change in clinical practice. Factors such as legal representation, compensation and claim type have been associated with increased health care utilisation following a motor vehicle crash (MVC) [44-46]. Further, comparing cross-sectional audits of practice conducted in similar cohorts across different time points will also help determine which changes in practice have been sustained over time.

This study therefore aimed to determine compliance of insurers and health professionals with the recommendations of the 2014 clinical practice guidelines for WAD and examine whether changes in professional practice have been sustained over time in light of previous investigations of WAD guideline implementation. In addition, this study aimed to explore claim-related factors associated with guideline compliance. Knowledge of compliance with guidelines in practice will form the basis for improving injury management processes and informing future implementation strategies.

\section{Methods}

\section{Study design}

This was an observational study that involved an audit of claimant files. Ethics approval was given by the Northern Sydney Local Health District Human Research Ethics Committee (LNR/16/HAWKE/78).

\section{Setting}

Four compulsory third party insurers in NSW, Australia agreed to participate in this study. New South Wales operates under a common law fault-based scheme where injury management costs are covered by compulsory third party (CTP) insurance. CTP insurance is underwritten by private insurance companies regulated by a government authority (SIRA). To be eligible for benefits people with WAD can submit a claim either within 28 days (ANF) or within 6 months (PICF) of the accident [47]. ANF allows early without prejudice access to treatments and payment for lost earnings up to $\$ 5000$ through acceptance of provisional liability. PICF covers expenses more than $\$ 5000$ and applies to those whose recovery would take longer than six months. Once liability is determined, requests for treatments are approved or declined on the basis of whether requests are reasonable and necessary. This can be determined through consideration of factors such as relationship of the service to the accident, benefit to the claimant, appropriateness of the service, appropriateness of the provider and cost [48]. Accordingly, there are no restrictions on the number and type of treatments permitted.

\section{Sample}

A random sample of 288 files, selected based on the relative market share of the insurers, was deemed to be representative. The sample was calculated from 1146 new claims submitted between 1 August 2015 and 15 November 2015, more than 6 months from the release of the most recent version of the guidelines in December 2014. This was necessary to provide adequate time for implementation and uptake of the recommendations. Inclusion criteria were; (1) whiplash as primary injury, (2) age of claimant $>17$, and (3) no fatality reported.

\section{Data source}

Primary sources of data were claim forms (e.g. ANF, PICF), medical certificate, NOC and review forms, and insurer file notes. The ANF and PICF, accompanied by a medical certificate, outline demographic and injury details, results of general medical practitioner (GP) assessment, request for imaging, referral to physical treatment (e.g. physiotherapy, chiropractic, etc.) and medications [49]. The NOC and review forms detail the physical treatment provider's treatment plan and requests for imaging and referral to other professionals [49]. Other data sources included practitioner reports, imaging reports, and invoices. Files were identified from the central database used by SIRA for claims management purposes and were made available to the research team in either paper or electronic format.

\section{Data collection}

Four researchers attended the participating insurer offices to extract data using a standard form. The standard form was a password-encrypted Excel spreadsheet created by the researchers to obtain relevant information to address the aims of the study. Another researcher randomly extracted data from $20 \%$ of all files to compare for agreement with the data extracted by other researchers. Fortnightly meetings were held to resolve disagreements and ensure consistency of data extraction.

Data extracted included demographic, claim and injury details, use of health services, and health professional and insurer practices. Demographic information included age, gender, employment status and postcode. Claim details included date of claim lodgement, claim status, claim type (i.e. ANF, full claim direct, full claim converted from ANF) and legal representation. Injury details included accident date and road user type. Use of health services provided information about access to recommended treatments and performance of the scheme and included timing and numbers of medical and 
physical treatments. Insurer and health professional practice related to compliance with guideline recommendations on classification, use of radiology, prognosis, treatment and referral (Additional file 1: Appendix 1) [29].

\section{Insurer compliance}

Insurer compliance with guideline recommendations was determined by extracting data on; requests made to the health professional for a Quebec Task Force (QTF) WAD grade (Additional file 1: Appendix 2), insurer-initiated screening of prognostic factors and referral to other health professionals. Information in relation to approval and denial of treatment (Table 4), imaging and referral requests was extracted. The time for insurer response to health professionals' treatment, imaging and referral requests, and reasons given were also obtained.

\section{Health professional compliance}

Health professional compliance with guideline recommendations on classification and radiology was determined by extracting data on; diagnostic labels used, and the timing and reasons given for radiological investigations. Compliance with prognosis recommendations was determined by evidence of use of recommended tools (Visual Analogue Scale (VAS), Numeric Rating Scale (NRS)), Neck Disability Index (NDI) [50], Impact of Events Scale (IES) [51] and other). Specific interventions (Table 4) provided were extracted and categorised as; first-line (recommended), adjunctive (not routinely recommended or no evidence), combined first-line and adjunctive, or not recommended. Lastly, data on the timing, reasons given for and outcome of referral to specialist WAD practitioners and/or psychologists were obtained. Specialist WAD practitioners are health professionals with expertise in the management of complex WAD and may include specialist physiotherapists and chiropractors, musculoskeletal medicine practitioners, rehabilitation physicians, pain medicine specialists or occupational physicians [29].

\section{Data analysis}

Data were analysed using descriptive statistics (mean \pm $\mathrm{SD}$; median(IQR); frequencies $(\mathrm{n}(\%)))$. Data for treatment were analysed across the time points; commencement of physical treatment, 6, 12 and 26 weeks post-injury, pertaining to acute, sub-acute and chronic periods of management, respectively. The time points were used as basis to determine whether the number of treatment sessions and provision of adjunctive treatments were tapering over time, for claims with multiple reviews. The researchers made judgements about WAD grade, indications for imaging and appropriateness of referral based on available file information.
Association of demographic factors (WAD grade, employment status) and claim characteristics (claim status, claim type, legal representation) with measures of guideline compliance (number of specialised imaging requests, number GP consults, cost of physical treatment) was determined using correlation analysis. The Shapiro-Wilk statistic revealed that the continuous data were not normally distributed; hence, non-parametric tests of association were used. Correlation coefficients were interpreted as: 0.00 to 0.29 , small; 0.30 to 0.49 , medium; and 0.50 to 1.0 , strong correlation [52]. Statistical analyses were performed using IBM SPSS Statistics v24. Common categories were generated for data entered in text.

\section{Results}

Data extraction occurred from March until October 2016 (Additional file 1: Appendix 3). Demographic, claim and injury details are summarised in Table 1.

\section{Classification of whiplash}

Insurers requested WAD grade in $6.9 \%$ of the files $(n=$ 20/288). Health professionals provided WAD grade in $13.0 \%$ of the files $(n=35 / 288)$. The most frequently reported diagnostic label was 'whiplash injury' $(n=156 /$ $288 ; 54.2 \%)$. Use of patho-anatomical terms was observed in $26.7 \%$ of the files $(n=77 / 288)$.

\section{Request for imaging}

Claimants received at least one form of imaging in $57.9 \%$ of the files $(n=167 / 288)$ (Table 2).

\section{Plain radiograph (cervical spine $x$-ray)}

The median time to insurer response to $x$-ray requests was 22 days. Five files $(8.1 \%)$ had documented approval of request to rule out cervical fracture and 5 requests (8.1\%) were declined for lack of clinical indications. There was no record of insurer response to the request in $79.0 \%(n=49 / 62)$ of the files.

X-rays were conducted for $28.1 \%$ of the claimants $(n=$ $81 / 288$ ). For $x$-rays conducted outside of emergency department (ED), $90.3 \%$ of the requests were made by the GP $(n=56 / 62)$ due to neck pain, tenderness, loss of motion $(n=22 / 62 ; 35.5 \%)$.

\section{Specialised imaging}

The median time to insurer response to specialised imaging requests was 15 days. Approval was given for $35.6 \%$ of the requests $(n=47 / 132)$ to clarify diagnosis. Twenty-one (15.9\%) requests were declined for lack of clinical indications. There was no record of insurer response to the request in $34.1 \%$ of the files $(n=45 / 132)$.

Almost half of the claimants received specialised imaging ( $n=141 / 288 ; 48.9 \%)$, with 80 claimants receiving 
Table 1 Demographic, claim, injury characteristics from a sample of WAD claims from four NSW CTP insurers

\begin{tabular}{|c|c|}
\hline All files & $N=288$ \\
\hline \multicolumn{2}{|l|}{ Demographic characteristics } \\
\hline Age, mean $\pm S D$ & $41.6 \pm 15.5$ \\
\hline Female, n (\%) & $171(59.4)$ \\
\hline \multicolumn{2}{|l|}{ Employment status, n (\%) } \\
\hline Employed & $166(57.6)$ \\
\hline Unemployed & $90(31.3)$ \\
\hline Self-employed & $32(11.1)$ \\
\hline \multicolumn{2}{|l|}{ Claim characteristics } \\
\hline \multicolumn{2}{|l|}{ Claim status, n (\%) } \\
\hline Open & $263(91.3)$ \\
\hline Finalised & $25(8.7)$ \\
\hline \multicolumn{2}{|l|}{ Type of claim, n (\%) } \\
\hline Accident notification form & $125(43.4)$ \\
\hline Full claim direct ${ }^{a}$ & $125(43.4)$ \\
\hline Full claim converted ${ }^{b}$ & $38(13.2)$ \\
\hline Legally represented, n (\%) & $166(57.6)$ \\
\hline \multicolumn{2}{|l|}{ Injury details } \\
\hline \multicolumn{2}{|l|}{ Road user type, n (\%) } \\
\hline Driver & $223(77.4)$ \\
\hline Passenger & $65(22.6)$ \\
\hline Injury count, median (IQR) & $2(2.0)$ \\
\hline \multicolumn{2}{|l|}{ WAD grade, $\mathrm{n}(\%)$} \\
\hline Grade I & $40(13.9)$ \\
\hline Grade ॥ & $230(79.9)$ \\
\hline Grade III & $15(5.2)$ \\
\hline Cannot determine & $3(1.0)$ \\
\hline
\end{tabular}

WAD whiplash associated disorder, SD standard deviation, IQR

interquartile range

${ }^{a}$ Full claim direct are claims lodged to access benefits more than $\$ 5000$ and where recovery is expected to last longer than 6 months. A PICF is submitted to the insurance company to access these benefits

${ }^{b}$ Full claim converted are claims that have initially been submitted through ANF but later on converted to full claim to access further benefits more than $\$ 5000$

at least one specialised imaging and 61 receiving more than one specialised imaging. The majority of specialised imaging was done outside of ED $(n=132 / 141 ; 93.6 \%)$ and requested by GPs $(n=100 / 132 ; 75.8 \%)$ for reasons such as neck pain, tenderness, loss of motion $(n=34$ / 132; 25.8\%). Magnetic resonance imaging (MRI) was most commonly requested $(n=86 / 186 ; 46.2 \%)$. The majority of those that received specialised imaging were claimants classified as WAD Grade II (Fig. 1).

Based on the review of all files and researcher judgment, 31.8\% $(n=42 / 132)$ of specialist imaging requests were considered compliant with the guidelines given presence of symptoms requiring further imaging to rule out possible neurological pathology.

\section{Assessment of prognostic indicators}

Insurers assessed prognostic indicators using recommended tools in less than $10 \%$ of the files (e.g. NRS; $n=$ 18/288; 6.3\%) (Table 3). Similarly, health professionals assessed these in $1.4 \%$ (e.g. IES; $n=4 / 288$ ) to $36.5 \%$ (e.g. VAS or NRS; $n=105 / 288$ ) of the files (Table 3). Health professionals also nominated other tools (e.g. Orebro Musculoskeletal Pain Questionnaire [53]) and factors (e.g. complex symptoms) to identify risk of non-recovery in 11.1 and $34.4 \%$ of the files, respectively.

\section{Treatments provided}

\section{Access to health care services}

The median time to GP consult was 4 days after injury and 25 days for physical treatment. The average number of GP consults was 5 sessions and 15 sessions for physical treatment. The majority of claimants $(n=250 / 288$; 86.8\%) were referred for physical treatment, of which 237 (94.8\%) had documented evidence of receiving treatment. The most common health professionals referred to were physiotherapists $(n=187 / 237 ; 78.9 \%)$. Approximately $13 \%(n=36 / 288)$ of claimants received physical treatment 1 week post-injury. The highest proportion of claimants receiving physical treatment was at 9 weeks post-injury ( $n=136 / 288 ; 47.2 \%$ ) (Fig. 2$)$, which decreased to $21.5 \%(n=62 / 288)$ at 26 weeks.

The median time to insurer response to physical treatment requests was 20 days after receipt of the NOC forms. Insurers approved 93\% ( $n=187 / 201)$ of physical treatment requests to promote early treatment, self-management and progress to functional recovery. Physical treatment request was denied in 5\% $(n=9 / 201)$ of the files for reasons including lack of evidence for physical benefit.

\section{Guideline-based treatment}

Few people with WAD received first-line treatments only $(n=3 / 201 ; 1.5 \%)$ and the majority received a combination of first-line and adjunctive treatments $(n=190 /$ 201; 94.5\%) (Fig. 3). This finding was consistent for claimants who were still undergoing treatments at 6,12 , and 26 weeks after commencement of physical treatment. The majority of claimants received neck exercises $(n=188$ / 209 ; $90 \%)$, advice $(n=165 / 205 ; 80.5 \%)$ and manual therapy $(n=189 / 201 ; 94 \%)$ (Table 4$)$. Few received treatments that are not recommended.

\section{Treatment frequency}

At the commencement of physical treatment, $45.8 \%$ ( $n$ $=92 / 201)$ of claimants had one session of physical treatment per week and 45.8\% ( $n=92 / 201)$ had 2 sessions per week (Fig. 4). There was evidence of tapering of treatment frequency over time, with the greatest reduction observed at 12 weeks after commencement of 
Table 2 Summary of imaging requests from a sample of WAD claims from four NSW CTP insurers

\begin{tabular}{|c|c|c|}
\hline Imaging requests & Cervical spine $x$-ray & Specialised imaging \\
\hline Received imaging, $\mathrm{n}(\%)$ & $N=288$ & $N=288$ \\
\hline Done at the emergency department & $19(6.6)$ & $9(3.1)$ \\
\hline Requested by the health professional & $62(21.5)$ & $132(45.8)$ \\
\hline Imaging requested by, $\mathrm{n}(\%)^{\mathrm{a}}$ & $N=62$ & $N=132$ \\
\hline General practitioner & $56(90.3)$ & $100(75.8)$ \\
\hline Allied health practitioner & $2(3.2)$ & $1(0.8)$ \\
\hline Medical specialist & $1(1.6)$ & $11(8.3)$ \\
\hline Other specialist & $2(3.2)$ & $0(0)$ \\
\hline More than one health professional & $0(0)$ & $16(12.1)$ \\
\hline No record & $1(1.6)$ & $4(3.0)$ \\
\hline Health professional justification, $\mathrm{n}(\%)^{\mathrm{a}}$ & $N=62$ & $N=132$ \\
\hline Neck pain, tenderness, loss of motion & $22(35.5)$ & $34(25.8)$ \\
\hline Motor vehicle accident & $11(17.7)$ & $9(6.8)$ \\
\hline Exclude fracture & $4(6.5)$ & $0(0)$ \\
\hline Radiculopathy, numbness, paraesthesia & $2(3.2)$ & $28(21.2)$ \\
\hline Headache, dizziness, nausea & $1(1.6)$ & $5(3.8)$ \\
\hline History of other conditions, prior injury & $1(1.6)$ & $3(2.2)$ \\
\hline Whiplash & $1(1.6)$ & $5(3.8)$ \\
\hline As advised by specialist & $0(0)$ & $5(3.8)$ \\
\hline None cited & $20(32.3)$ & $43(32.6)$ \\
\hline Timeframe (days), median (IQR) ${ }^{a}$ & $N=62$ & $N=132$ \\
\hline Time to request & $6.5(24)$ & $45(123)$ \\
\hline Time to receipt & $25(34)$ & $54.5(102)$ \\
\hline
\end{tabular}

WAD whiplash associated disorder, IQR interquartile range

${ }^{\text {a }}$ from claimants receiving imaging outside of emergency department

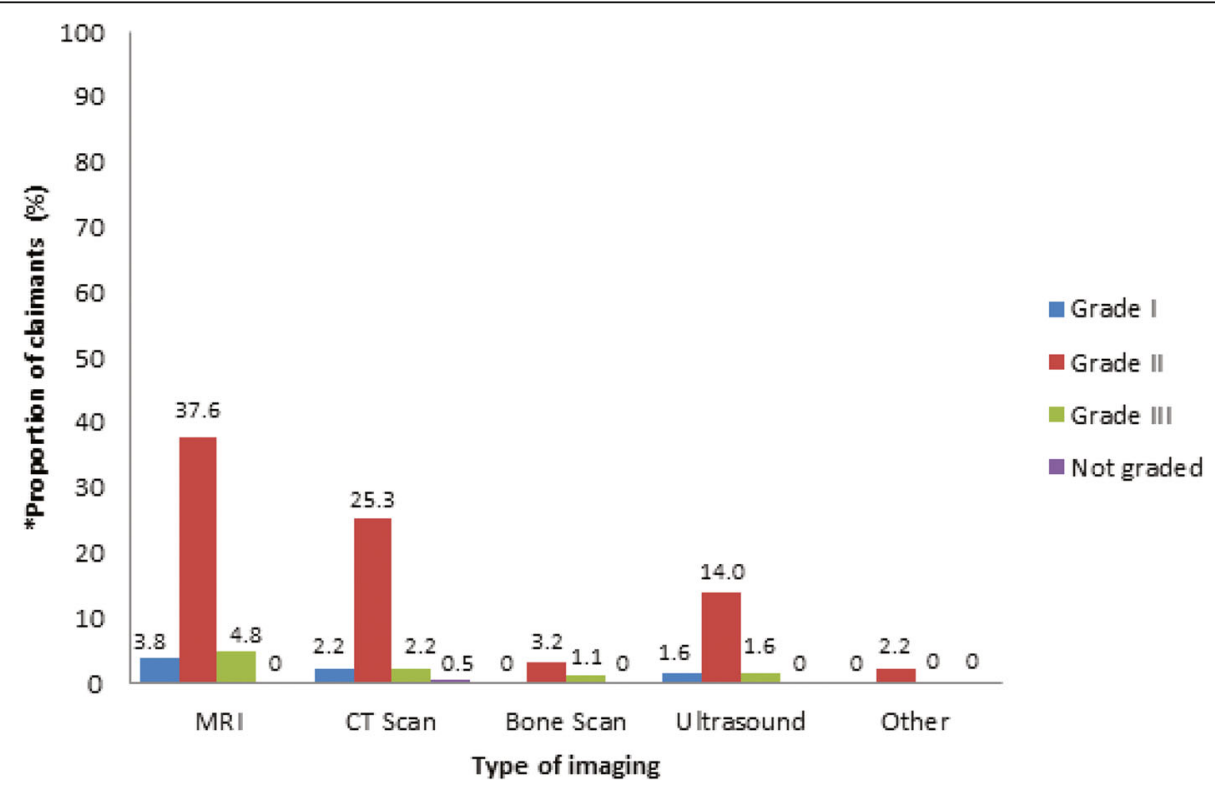

Fig. 1 Type of specialised imaging received by WAD claimants according to WAD grade. WAD, whiplash associated disorder; MRI, magnetic resonance imaging; $C T$, computed tomography. ${ }^{*}$ data obtained from all records of specialised imaging received by claimants $(N=186)$ 
Table 3 Assessment of prognostic indicators from a sample of WAD claims from four NSW CTP insurers

\begin{tabular}{|c|c|c|}
\hline & Insurer & Health professional \\
\hline & $N=288$ & $N=288$ \\
\hline Pain (VAS/NRS), n(\%) & $18(6.3)$ & $105(36.5)$ \\
\hline Disability (NDI) [50], n(\%) & $0(0)$ & $37(12.8)$ \\
\hline Expectation of recovery, $\mathrm{n}(\%)$ & $24(8.3)$ & $7(2.4)$ \\
\hline Impact of events (IES) [51], n(\%) & $0(0)$ & $4(1.4)$ \\
\hline Other prognostic tools, n(\%) & & $32(11.1)$ \\
\hline Orebro Musculoskeletal Pain Questionnaire [53] & & $6(2.1)$ \\
\hline Patient Specific Functional Scale [89] & & $4(1.4)$ \\
\hline Depression, Anxiety, Stress Scales 21 [90] & & $6(2.1)$ \\
\hline Copenhagen Neck Functional Disability Scale [91] & & $2(0.7)$ \\
\hline Whiplash Disability Questionnaire [92] & & $2(0.7)$ \\
\hline Oswestry Low Back Pain Questionnaire [93] & & $3(1.0)$ \\
\hline Roland Morris Disability Questionnaire [93] & & $5(1.7)$ \\
\hline Functional Rating Index [94] & & $4(1.4)$ \\
\hline Other factors identified, $\mathrm{n}(\%)$ & & $99(34.4)$ \\
\hline Complex symptoms & & $54(18.8)$ \\
\hline Multiple injuries & & $14(4.9)$ \\
\hline Age & & $3(1.0)$ \\
\hline Nature of work & & $9(3.1)$ \\
\hline Previous neck injury & & $5(1.7)$ \\
\hline Delayed treatment & & $5(1.7)$ \\
\hline Poor fitness/health prior to injury & & $3(1.0)$ \\
\hline Chronicity of the condition & & $4(1.4)$ \\
\hline Medication & & $1(0.3)$ \\
\hline High impact collision & & $1(0.3)$ \\
\hline
\end{tabular}

VAS Visual Analogue Scale, NRS Numeric Rating Scale, NDI Neck Disability Index, IES Impact of Events Scale

physical treatment. At 26 weeks, $10 \%$ of claimants were still having physical treatments once a week.

\section{Referral to other professionals}

Over half of the claimants $(n=170 / 288 ; 59.0 \%)$ were referred to other professionals (Fig. 5).

\section{Specialist referral}

The median time to insurer response to specialist referral was 18 days. Request for specialist referral was approved in $20.5 \%$ of the files $(n=24 / 117)$ to confirm diagnosis, assess current status, review appropriateness of treatment and provide recommendations on rehabilitation needs. Insurers declined $10 \%$ of specialist referrals ( $n=11 / 117)$ due to lack of indicators for specialist consult.

One-hundred-seventeen claimants ( $n=117 / 170 ; 68.8 \%)$ were referred to specialists (Table 5). Of these, $43.6 \%$ ( $n=$ $51 / 117)$ involved referral to surgical specialists and $20.5 \%$ $(n=24 / 117)$ to WAD specialists. The main justification for specialist referral was to obtain opinions about diagnosis and management ( $n=63 / 117 ; 53.8 \%)$. The median time for referral to specialists was 89 days. Outcomes of referral included clarification of condition $(n=26 / 117$; $22.2 \%)$ and request for further imaging and tests $(n=11 /$ $117 ; 9.4 \%)$.

Based on review of files and researcher judgment, an additional $19.1 \%$ of claimants $(n=55 / 288)$ would have benefited from WAD specialist consult where no referral was made. These indications were obtained from reports of apparent non-recovery at review and presence of high-risk factors, such as high pain and disability.

\section{Psychologist referral}

The median time to insurer response to psychology referral was 44 days. Insurers approved $54.7 \%$ of the referral requests $(n=29 / 53)$ to address psychological needs and declined $13.2 \%$ of the requests $(n=7 / 53)$ due to lack of indicators.

Fifty-three claimants $(n=53 / 170 ; 31.2 \%)$ were referred to psychologists due to presence of anxiety and fear of 


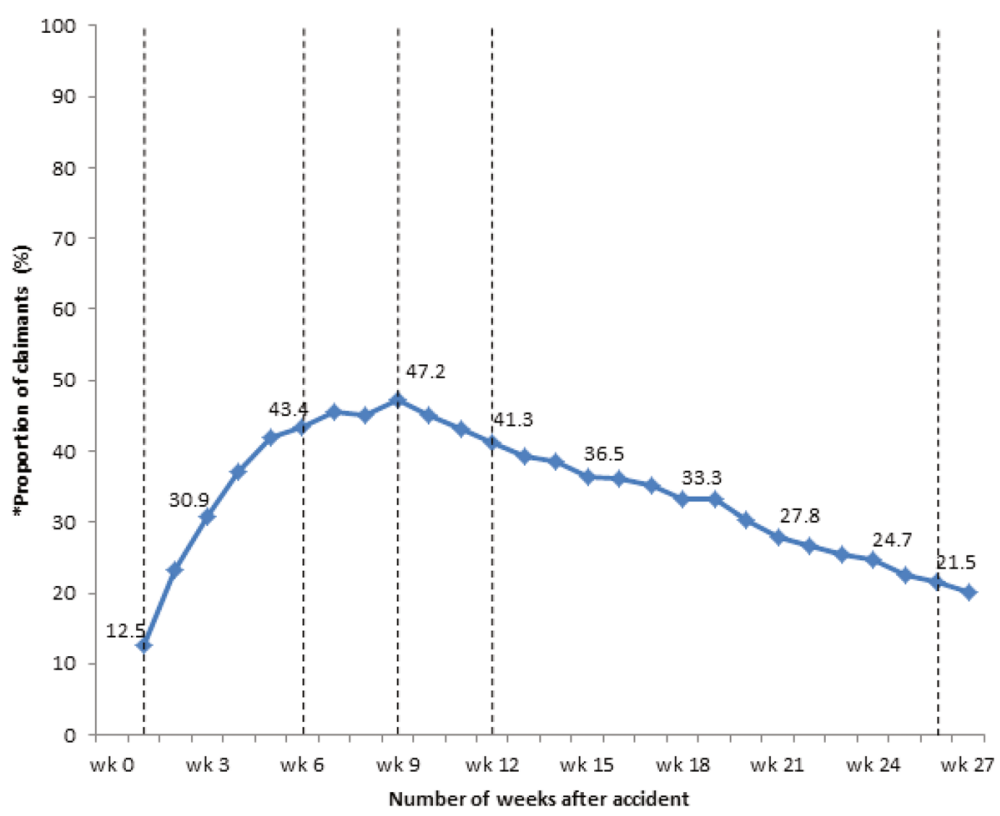

Fig. 2 Proportion of WAD claimants accessing physical treatment from the time of accident. ${ }^{*}$ data obtained from all files $(N=288)$

driving $(n=22 / 53 ; 41.5 \%)$ (Table 6). The median time for referral to psychologists was 63 days.

Based on review of files and researcher judgment, $73.6 \%$ $(n=39 / 53)$ of the referrals made to psychologists were considered appropriate to address psychological symptoms. There was also a proportion of claimants deemed that would have benefited from psychologist consult due to reported presence of psychological symptoms $(n=51$ / 288; 17.7\%); however, no referral was made.

\section{Association of claim factors with measures of guideline compliance}

There was moderate correlation between full claim and increased number of specialised imaging received $(\rho=$ $0.30, p<0.01$ ), and between open claim and increased number of GP consults $(\rho=0.30, p<0.01)$. A small correlation was observed between legal representation and increased number of specialised imaging received $(\rho=$ $0.24, p<0.01)$ and GP consults $(\rho=0.23, p<0.01)$,

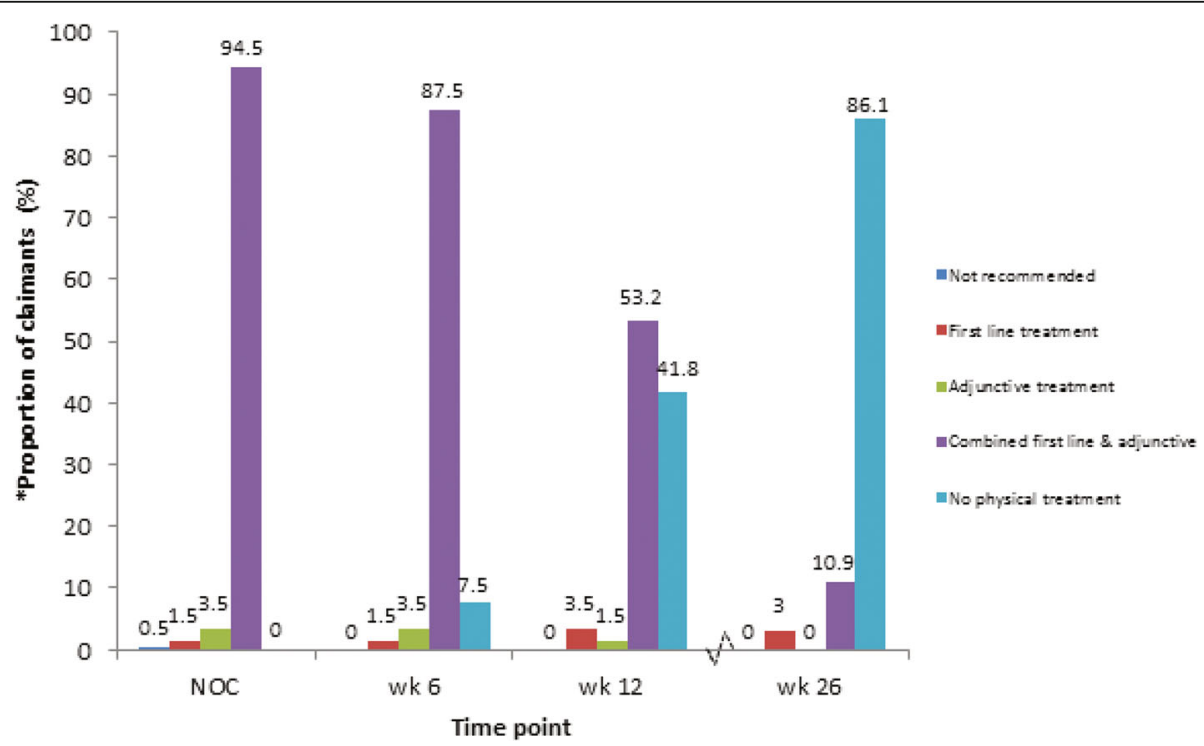

Fig. 3 Type of treatments received by WAD claimants over a period of 6 months. * data obtained from claimants receiving physical treatment with documentation submitted $(N=201)$ 
Table 4 Guideline-based interventions from a sample of WAD claims from four NSW CTP insurers

\begin{tabular}{|c|c|c|c|c|}
\hline \multirow{3}{*}{ Recommended- evidence of benefit } & \multirow[b]{2}{*}{ Grade $^{a}$} & \multirow[b]{2}{*}{$\mathrm{N}$} & \multirow{2}{*}{$\begin{array}{l}\text { Physical treatment } \\
\% N=201\end{array}$} & \multirow{2}{*}{$\begin{array}{l}\text { All files } \\
\% N=288\end{array}$} \\
\hline & & & & \\
\hline & & & & \\
\hline Neck Exercises & B & 188 & $90.0^{\phi}$ & 65.3 \\
\hline Advice & B & 165 & $80.5^{\wedge}$ & 57.3 \\
\hline Reassurance & B & 50 & $24.5^{\delta}$ & 17.4 \\
\hline \multicolumn{5}{|l|}{ Pain-relieving medications } \\
\hline Non-steroidal anti-inflammatory drugs & $\square$ & 106 & & 36.8 \\
\hline Simple analgesics & $\square$ & 95 & & 33.0 \\
\hline Opioids & $\square$ & 64 & & 22.2 \\
\hline \multicolumn{5}{|l|}{ Not routinely recommended- limited evidence } \\
\hline Manual therapy & $\mathrm{C}$ & 189 & 94.0 & 65.6 \\
\hline Trigger point needling & $\mathrm{D}$ & 19 & 9.5 & 6.6 \\
\hline Acupuncture & $\mathrm{D}$ & 14 & 7.0 & 4.9 \\
\hline Taping & $\mathrm{C}$ & 14 & 7.0 & 4.9 \\
\hline \multicolumn{5}{|l|}{ No evidence of benefit or harm } \\
\hline Electrotherapy & $\square$ & 71 & 35.3 & 24.7 \\
\hline Massage & $\nabla$ & 33 & 16.4 & 11.5 \\
\hline Heat/lce & $\nabla$ & 17 & 8.5 & 5.9 \\
\hline Traction & $\nabla$ & 3 & 1.5 & 1.0 \\
\hline Pilates/Yoga & $\square$ & 3 & 1.5 & 1.0 \\
\hline Pillow & $\square$ & 2 & 1.0 & 0.7 \\
\hline Cupping & $\square$ & 1 & 0.5 & 0.3 \\
\hline \multicolumn{5}{|l|}{ Not recommended-evidence of no benefit } \\
\hline Anti-depressant & $\nabla$ & 14 & & 4.9 \\
\hline Intra-articular and intrathecal steroid injection & $\square$ & 10 & & 3.5 \\
\hline Muscle relaxant & B & 8 & & 2.8 \\
\hline Collar & A & 8 & & 2.8 \\
\hline Anti-convulsant & $\square$ & 7 & & 2.4 \\
\hline Reduction of usual activities for more than 4 days & $\square$ & 0 & & 0 \\
\hline Botulinum toxin type $A$ & A & 0 & & 0 \\
\hline Pulsed electromagnetic treatment & $\nabla$ & 0 & & 0 \\
\hline
\end{tabular}

WAD whiplash associated disorder, NSW New South Wales, CTP compulsory third party, IQR interquartile range $\phi_{N}=209 ;{ }^{\wedge} N=205 ;{ }^{\delta} N=204$

${ }^{a}$ Grade of recommendation [29] = A, body of evidence can be trusted to guide practice; B, body of evidence can be trusted to guide practice in most situations; C, body of evidence provides some support for recommendations but care should be taken in its application; D, body of evidence is weak and recommendation must be applied with caution; , consensus recommendation supported by all members of the working group as a graded recommendation could not be made due to lack of evidence

and higher total cost of physical treatment $(\rho=0.23$, $p<0.01)$.

\section{Discussion}

This study shows that health professionals have adopted some of the guideline recommendations when assessing and treating people with WAD. However, there are some aspects of insurer and health professional practice that are not aligned with key recommendations of the guidelines. Specialised imaging and passive treatments are being provided and approved in a large proportion of claims and monitoring of prognosis and appropriate specialist referral are not being sought by providers or insurers in a large proportion of claims. These practices have been identified as priority areas for improvement in light of the new legislation, the Motor Accidents Injuries Act 2017, which limits benefits for minor injuries such as WAD to 6 months. In the following discussion, 


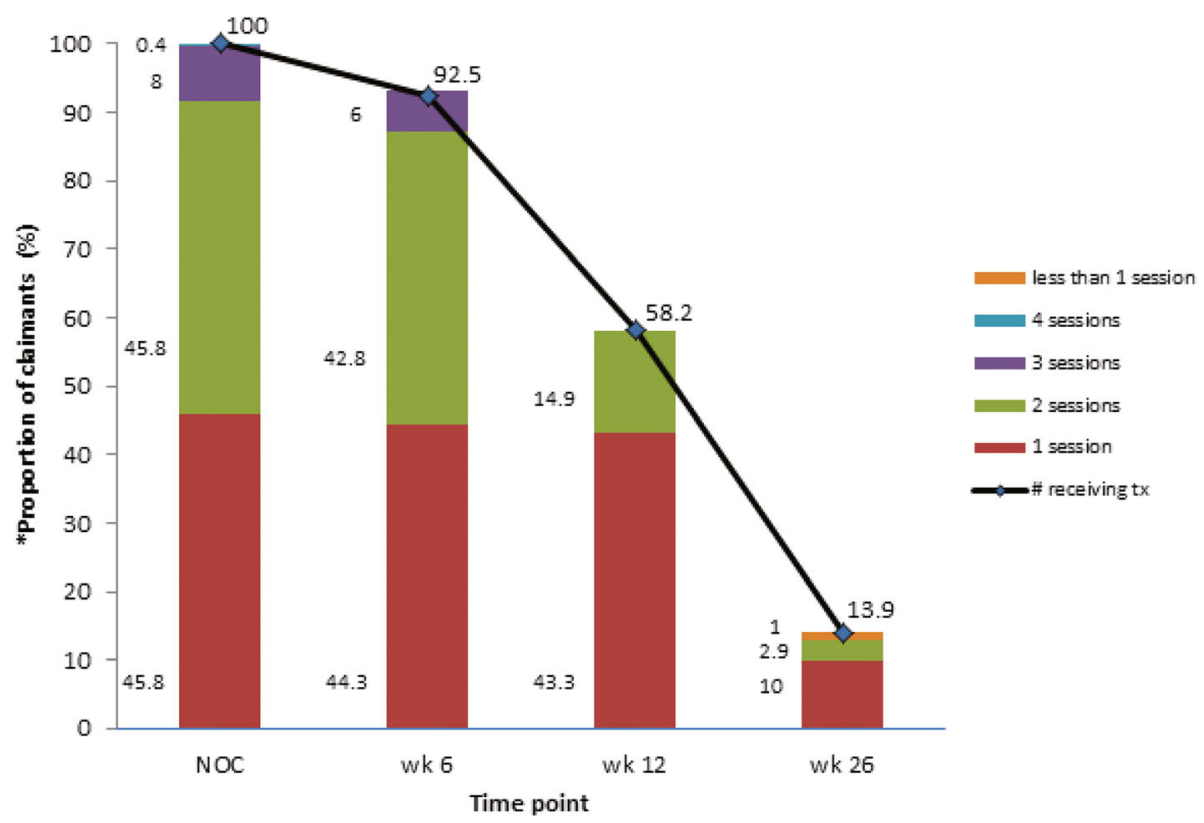

Fig. 4 Proportion of WAD claimants receiving treatment and treatment frequency over a period of 6 months. ${ }^{*}$ data obtained from claimants receiving physical treatment with documentation submitted $(N=201)$

suggestions will be made regarding strategies to facilitate compliance with recommendations of the WAD guidelines to ultimately improve outcomes for WAD.

These findings suggest that previous implementation strategies and guideline review since 1999 have been effective in changing aspects of WAD management $[10,34-37]$. Rates of $x$-ray investigation in this study
(21.5\%) were relatively low compared to the rates reported from the year 2000 to 2009 (30.0\%) [54]. This is consistent with previous work in Canada and Australia where rates of $x$-ray investigations following WAD reduced following education and training of physicians, ED staff and nurses on use of the Canadian C-spine rule [55]. In addition, neck exercises and advice to keep active are

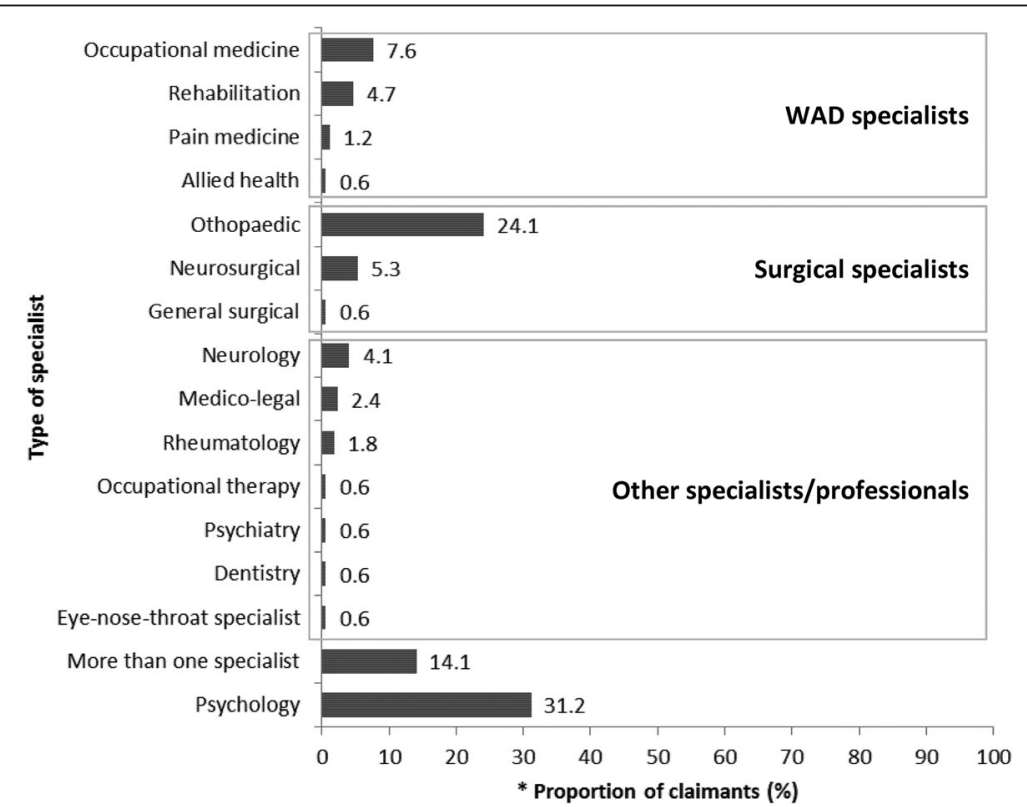

Fig. 5 Referral to other professionals from a sample of WAD claims from four NSW CTP insurers. * data obtained from claimants who were referred to other professionals $(N=170)$ 
Table 5 Referral to specialists from a sample of WAD claims from four NSW CTP insurers

\begin{tabular}{|c|c|c|c|}
\hline \multirow{2}{*}{ 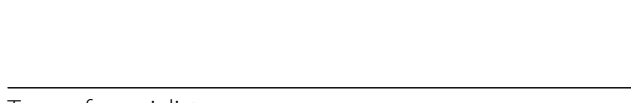 } & \multirow[t]{2}{*}{$\mathrm{N}$} & \multirow{2}{*}{$\begin{array}{l}\text { Referred \% } \\
N=117\end{array}$} & \multirow{2}{*}{$\begin{array}{l}\text { All files } \% \\
N=288\end{array}$} \\
\hline & & & \\
\hline \multicolumn{4}{|l|}{ Type of specialist } \\
\hline Surgical specialists & 51 & 43.6 & 17.7 \\
\hline WAD specialists & 24 & 20.5 & 8.3 \\
\hline Other specialists & 18 & 15.4 & 6.3 \\
\hline More than one specialist & 24 & 20.5 & 8.3 \\
\hline \multicolumn{4}{|l|}{ Referral source } \\
\hline General practitioner & 62 & 53.0 & 21.5 \\
\hline Insurer & 32 & 27.4 & 11.1 \\
\hline Solicitor & 16 & 13.7 & 5.6 \\
\hline Medical specialist & 5 & 4.3 & 1.7 \\
\hline Physiotherapist & 2 & 1.7 & 0.7 \\
\hline \multicolumn{4}{|l|}{ Health professional justification } \\
\hline Opinion about diagnosis and management & 63 & 32.5 & 21.9 \\
\hline Complexity and severity of the injury & 8 & 6.8 & 2.8 \\
\hline Persistent pain, non-recovery & 6 & 5.1 & 2.1 \\
\hline Surgical management, specialised procedures & 2 & 1.7 & 0.7 \\
\hline Needs assessment & 2 & 1.7 & 0.7 \\
\hline None cited & 36 & 30.8 & 12.5 \\
\hline Indicated for WAD specialist but no referral made & 55 & & 19.1 \\
\hline \multicolumn{4}{|l|}{ Timeframe (days), median(IQR) } \\
\hline Time to request & 89(158) & & \\
\hline \multicolumn{4}{|l|}{ Outcome of specialist referral } \\
\hline Clarification of condition, assessment of impairment & 26 & 22.2 & 9.0 \\
\hline Further imaging and tests & 11 & 9.4 & 3.8 \\
\hline Continuation of current management & 8 & 6.8 & 2.8 \\
\hline Pain management (medications, injections) & 6 & 5.1 & 2.1 \\
\hline Referral to another health professional & 5 & 4.3 & 1.7 \\
\hline Rehabilitation plan & 2 & 1.7 & 0.7 \\
\hline Discontinuation of treatment & 2 & 1.7 & 0.7 \\
\hline Return to work & 2 & 1.7 & 0.7 \\
\hline No record & 55 & 47.0 & 19.1 \\
\hline
\end{tabular}

WAD whiplash associated disorder, NSW New South Wales, CTP compulsory third party, IQR interquartile range

being provided by health professionals and approved by insurers for the majority of claimants, demonstrating widespread acceptability of these guideline recommendations. Positive results of implementation strategies support the value of continuing education among insurers and health professionals about WAD guidelines.

These results also reveal that insurer claims management processes can facilitate early access to and approval of treatments and contribute to improved scheme performance. Claimants are using the ANF type of claim effectively, with $56 \%$ of claims lodged initially through this system and approved by insurers. Moreover, the median time to commencing physical treatment was 3 weeks post-MVC. These results show that claimants are taking advantage of provisional liability and accessing treatments earlier than they would have if they had to wait for full admission of liability. In a study comparing outcomes and costs for WAD pre and post the 1999 legislative reform in NSW, medical expenses in the first 6 months post-injury were higher at 2 and 4 years after the reform, indicating early access to treatment was achieved [56]. This study suggests compliance with legislative intent of the Motor Accidents Compensation Act 1999 to provide early access to treatments for people with WAD. 
Table 6 Referral to psychologists from a sample of WAD claims from four NSW CTP insurers

\begin{tabular}{llll}
\hline & $N$ & Referred \% & All files $\%$ \\
$N=288$
\end{tabular}

WAD whiplash associated disorder, NSW New South Wales, CTP compulsory third party, IQR interquartile range

Whilst the current study found evidence of compliance by insurers and health professionals with some guideline recommendations, other observed practices such as not using the QTF WAD classification system and unnecessary specialised imaging demonstrate non-compliance. Health professionals commonly used "whiplash injury" (54.2\%) or patho-anatomical diagnoses (26.7\%), rather than the QTF classification. Further, high rates of MRI were observed despite majority of claimants being classified as Grade II, which is consistent with pursuing a patho-anatomical diagnosis. Use of unnecessary imaging in WAD has also been observed in Victoria, Australia [54], and in American and Australian cohorts investigating low back pain $[57,58]$. This practice is not recommended given the lack of association between imaging findings and clinical symptoms [59-65], and adverse outcomes associated with unnecessary imaging [66-69]. The patterns observed in the current study and that of others suggest a dominant biomedical approach to management, which conflicts with the biopsychosocial approach advocated by the guidelines.

The high proportion of claimants receiving passive treatments beyond the acute phase of injury ( $>12$ weeks) may also reflect an approach that is inconsistent with guideline recommendations. Manual therapy is often provided for people with WAD in other countries [70, 71], suggesting that a proportion of health professionals continue to utilise a symptom-focused approach in management. Whilst the provision of manual (passive) therapy is recommended as an adjunct to active treatment in the acute phase of WAD, the persistence of providing this without evidence of benefit is not recommended as it promotes passive coping strategies and poor self-efficacy $[29,72-74]$. Given both these factors are associated with non-recovery $[75,76]$, empowering the injured person to manage their symptoms is recommended to improve health outcomes [6].

Further, both insurer and health professional practices demonstrate non-compliance with identification of claimants at risk of non-recovery and acting on this with timely and appropriate referral. Health professionals and insurers inconsistently used validated prognostic tools and rarely reported on expectation of recovery. Most referrals were made to surgical specialists, arguably too late ( $>13$ weeks) to influence the course of recovery as studies on WAD recovery trajectories demonstrate that most recovery occurs within 12 weeks of injury [30, 77-79]. Additionally, recent legislative reform in NSW (Motor Accidents Injuries Act 2017 No 10) will limit access to benefits to 6 months for people with minor injuries such as WAD. Thus, the recommendation in guidelines is for onward referral between 3 and 6 weeks to address non-recovery [29]. The change in the scheme, guideline recommendations on referral and data on recovery trajectories emphasize the importance of ensuring treatments maximise the potential for recovery and limit chronicity. 
Given that implementation strategies to date (e.g. dissemination of guidelines, educational workshops, online education) have not been completely successful in promoting compliance with all of the recommendations in the guidelines, alternative strategies may need to be considered. One strategy may be to implement organisational changes such as mandating practice through policy or within insurer claims management processes. Regulatory or legislative changes may also be implemented by the insurance regulator to involve restrictions in payment of treatment requests or having a reasonable cap for number of treatments provided. Evidence in other settings showed that changing policies at the level of the organisation resulted to changes in practice. Reimbursement restriction policies decreased inappropriate medication prescribing [80], and promoted better use of medications with reduced costs without an increase in utilisation of other health services [81].

At the level of the insurers, changes in claims management processes may include mandated use of validated risk screening tools, such as the clinical prediction rule for WAD $[82,83]$, and mandated peer review by WAD specialists based on risk of non-recovery. Such practices have demonstrated effect; implementing use of screening tools such as the Canadian C-spine rule as a policy within a community hospital ED led to a significant reduction in $\mathrm{x}$-ray requests [84]. Further, results of a study among injured workers showed that mandated risk assessment and early referral to psychologists of those at high-risk of delayed recovery improved outcomes and reduced costs [85]. A qualitative study exploring the perceptions of health professionals on WAD specialist referral also suggested that a standardised process for specialist review mandated by the insurers might promote good referral practices [86]. Another strategy could be to use WAD-specific standard reporting and referral forms, a strategy shown to improve compliance in other health populations $[87,88]$.

Professional implementation strategies have been effective in instigating practice change; however, there are entrenched behaviours remaining unchanged and appeared to be influenced by scheme and compensation factors. Results of the current study showed that having legal representation and full, ongoing claims were associated with higher number of medical visits, specialised imaging and cost of treatment. Although associations were weak to moderate, these results highlight that organisational and regulatory changes, in addition to professional implementation strategies, may be necessary to change practice.

\section{Limitations}

Whilst data were extracted from all available sources, this study was limited by the completeness of the files.
The majority of the claimant files were open, ongoing claims at the time of data extraction; hence, some data were not available (e.g. insurer correspondence). Another limitation could be that the files were obtained from new claims submitted approximately 8 months after the release of the most recent WAD guidelines. Insufficient time may have elapsed for the guideline recommendations to be adopted in practice. Additionally, only insurer files were audited; hence, details of specific treatments and management decisions made by health professionals may not have been adequately captured. Lastly, results may not be generalised to practices not operating within the same healthcare and compulsory third party insurance systems as management processes and decisions may differ.

\section{Conclusion}

In summary, there is evidence of insurer and health professional practices that are compliant with recommendations from WAD guidelines. Claimants receive early access to and approval of appropriate care. However, there is also evidence of practices that are not compliant and might lead to poor health outcomes and greater treatment costs. Alternate implementation strategies may need to be considered to reduce unnecessary imaging and the persistent provision of passive treatments; promote use of validated prognostic tools; and maximise early referral to WAD specialists and psychologists. It appears that multiple strategies involving organisational, regulatory and professional interventions may be necessary to successfully implement the recommendations of the WAD guidelines to change practice, improve scheme performance and ultimately improve outcomes for people with WAD.

\section{Additional file}

Additional file 1: Appendix 1. Insurer and health professional data collected based on recommendations of the guidelines. Appendix 2. Quebec Task Force classification of grades of WAD. Appendix 3. Flow diagram of claimant files included in the study. (DOCX $37 \mathrm{~kb}$ )

\footnotetext{
Abbreviations

ANF: Accident notification form; CTP: Compulsory third party; ED: Emergency department; GP: General medical practitioner; IES: Impact of events scale; IQR: Interquartile range; MRI: Magnetic resonance imaging; MVC: Motor vehicle crash; NDI: Neck disability index; NOC: Notification of commencement; NRS: Numeric rating scale; NSW: New South Wales; QTF: Quebec Task Force; SD: Standard deviation; SIRA: State Insurance Regulatory Authority; VAS: Visual analogue scale; WAD: Whiplash associated disorder
}

\section{Acknowledgements}

The research team would like to acknowledge the insurance providers that agreed to participate in this study and the claims managers who assisted us during data collection. We also acknowledge the State Insurance Regulatory Authority for supporting this research. ANB was supported by scholarships from the University of the Philippines Expanded Modernization Program - 
Doctoral Studies Fund and the University of Sydney Non-established Postgraduate Award. RM was supported by a career fellowship from the New South Wales Ministry of Health under the New South Wales Health Early-Mid Career Fellowships Scheme. IC was supported by a NHMRC Practitioner Fellowship. TR was supported by an early career NHRMC Health Practitioner Research Fellowship.

\section{Funding}

Funding for this study was provided by the State Insurance Regulatory Authority of New South Wales, Australia. The funding body was not involved in any aspect of the study- data collection, analysis, interpretation of results, and writing of the manuscript.

\section{Availability of data and materials}

Data extraction form and de-identified coded data used in the current study are available from the corresponding author upon reasonable request.

\section{Authors' contributions}

ANB contributed to ethics application, data collection, analysis, interpretation and drafted the manuscript for this study. ANB also acted as study coordinator prior to commencement of the study and during data collection. AL was involved in project design, data collection, analysis, interpretation and critical appraisal of the manuscript. MM participated in data analysis, interpretation and critical appraisal of the manuscript. RI, SS, CC participated in data collection and critical appraisal of the manuscript. NM, $\mathrm{RM}, \mathrm{ED}$, EL were involved in data collection, project design, and appraisal of the manuscript. IC and TR designed the project, drafted the funding application and critically appraised the manuscript. TR further participated in data collection, analysis and interpretation of results. All authors were involved in manuscript revision and agreed on the final version of the manuscript for submission.

\section{Ethics approval}

The Northern Sydney Local Health District Human Research Ethics Committee (LNR/16/HAWKE/78) approved the conduct of this study, along with execution of confidentiality agreements with participating insurance providers.

\section{Consent for publication}

Not applicable.

\section{Competing interests}

The authors declare that they have no competing interests.

\section{Publisher's Note}

Springer Nature remains neutral with regard to jurisdictional claims in published maps and institutional affiliations.

\section{Author details \\ ${ }^{1}$ Faculty of Health Sciences, The University of Sydney, 75 East Street, Sydney, Australia. ${ }^{2}$ College of Allied Medical Professions, University of the Philippines, Manila, Philippines. ${ }^{3}$ John Walsh Centre for Rehabilitation Research, Royal North Shore Hospital, Sydney, Australia. ${ }^{4}$ Faculty of Medicine and Health Sciences, Macquarie University, Sydney, Australia. ${ }^{5}$ Macquarie University, Australian Institute of Health Innovation, Sydney, Australia. ${ }^{6}$ Musculoskeletal Lab/Refshauge Lab (S218), Faculty of Health Sciences, The University of Sydney - Cumberland Campus, 75 East Street, Lidcombe, NSW 2141, Australia.}

Received: 2 March 2018 Accepted: 1 August 2018 Published online: 08 August 2018

\section{References}

1. Ferrari R, Russell AS. Neck pain. Best Pract Res Clin Rheumatol. 2003;17(1): 57-70. https://doi.org/10.1053/yberh.2003.269.

2. Martin BI, Deyo RA, Mirza SK, Turner JA, Comstock BA, Hollingworth W, et al. Expenditures and health status among adults with back and neck problems. JAMA. 2008;299(6):656-64.

3. Goode AP, Freburger J, Carey T. Prevalence, practice patterns, and evidence for chronic neck pain. Arthritis Care Res. 2010;62(11):1594-601. https://doi. org/10.1002/acr.20270.
4. Ivanova JI, Birnbaum HG, Schiller M, Kantor E, Johnstone BM, Swindle RW. Real-world practice patterns, health-care utilization, and costs in patients with low back pain: the long road to guideline-concordant care. Spine J. 2011;11:622-32. https://doi.org/10.1016/j.spinee.2011.03. 017.

5. Mafi JN, McCarthy EP, Davis RB, London BE. Worsening trends in the management and treatment of back pain. JAMA Intern Med. 2013;173(17): 1573-81. https://doi.org/10.1001/jamainternmed.2013.8992.

6. Transport Accident Commission, WorkSafe Victoria. Clinical Framework for the Delivery of Health Services. Transport Accident Commission; 2012. https://www.tac.vic.gov.au/_data/assets/pdf_file/0010/27595/dinicalframework-single.pdf. Accessed 17 July 2017.

7. Grimshaw J, Eccles M, Tetroe J. Implementing clinical guidelines: current evidence and future implications. J Contin Educ Heal Prof. 2004;24(Supp 1): S31-7. https://doi.org/10.1002/chp.1340240506.

8. Grol R, Wensing M. What drives change? Barriers to and incentives for achieving evidence-based practice. Med J Aust. 2004;180(Supp 6):S57-60.

9. National Institute for Health and Clinical Excellence. How to change practice. 2007. https:/www.nice.org.uk/media/default/about/what-we-do/ into-practice/support-for-service-improvement-and-audit/how-to-changepractice-barriers-to-change.pdf. Accessed 9 Nov 2017.

10. van der Wees PJ, Jamtvedt G, Rebbeck T, de Bie RA, Dekker J, Hendriks EJ. Multifaceted strategies may increase implementation of physiotherapy clinical guidelines: a systematic review. Aust J Physiother. 2008;54(4):233-41. https://doi.org/10.1016/S0004-9514(08)70002-3.

11. French SD, Green S, Buchbinder R, Barnes $\mathrm{H}$. Interventions for improving the appropriate use of imaging in people withmusculoskeletal conditions. Cochrane Database Syst Rev. 2010;1:CD006094. https://doi.org/10.1002/ 14651858.CD006094.pub2.

12. Lineker SC, Husted JA. Educational interventions for implementation of arthritis clinical practice guidelines in primary care: effects on health professional behavior. J Rheumatol. 2010;37(8):1562-9. https://doi.org/10. 3899/jrheum.100045.

13. Suman A, Dikkers MF, Schaafsma FG, van Tulder MW, Anema JR. Effectiveness of multifaceted implementation strategies for the implementation of back and neck pain guidelines in health care: a systematic review. Implement Sci. 2016;11(1):126. https://doi.org/10.1186/ s13012-016-0482-7.

14. Tzortziou Brown V, Underwood M, Mohamed N, Westwood O, Morrissey D. Professional interventions for general practitioners on the management of musculoskeletal conditions. Cochrane Database Syst Rev. 2016;5:CD007495. https://doi.org/10.1002/14651858.CD007495.pub2.

15. Berube ME, Poitras S, Bastien M, Laliberte LA, Lucharite A, Gross DP. Strategies to translate knowledge related to common musculoskeletal conditions into physiotherapy practice: a systematic review. Physiotherapy. 2017. https://doi.org/10.1016/j.physio.2017.05.002.

16. Neath A. Complexity of sustaining healthcare improvements: what have we learned so far? NHS modernisation agency. 2004. https://www. qualitasconsortium.com/index.cfm/reference-material/service-transformation/ complexity-of-sustaining-improvements/. Accessed 3 Nov 2017.

17. Virani T, Lemieux-Charles L, Davis DA, Berta W. Sustaining change: once evidence-based practices are transferred, what then? Healthc Q. 2009; 12(1):89-96.

18. Hoomans T, Ament AJ, Evers SM, Severens JL. Implementing guidelines into clinical practice: what is the value? J Eval Clin Pract. 2011;17(4):606-14. https://doi.org/10.1111/j.1365-2753.2010.01557.x.

19. Oakeshott P, Kerry SM, Williams JE. Randomized controlled trial of the effect of the Royal College of Radiologists' guidelines on general practitioners' referrals for radiographic examination. Br J Gen Pract. 1994:44(382):197-200

20. Kerry S, Oakeshott P, Dundas D, Williams J. Influence of postal distribution of the Royal College of Radiologists' guidelines, together with feedback on radiological referral rates, on $\mathrm{X}$-ray referrals from general practice: a randomized controlled trial. Fam Pract. 2000;17(1):46-52.

21. Eccles M, Steen N, Grimshaw J, Thomas L, McNamee P, Soutter J, et al. Effect of audit and feedback, and reminder messages on primary-care radiology referrals: a randomised trial. Lancet. 2001;357(9266):1406-9. https://doi.org/10.1016/S0140-6736(00)04564-5.

22. Ramsay CR, Eccles M, Grimshaw JM, Steen N. Assessing the long-term effect of educational reminder messages on primary care radiology referrals. Clin Radiol. 2003;58(4):319-21. 
23. Ammendolia C, Hogg-Johnso S, Pennick V, Glazier R, Bombardier C. Implementing evidence-based guidelines for radiography in acute low back pain: a pilot study in a chiropractic community. J Manip Physiol Ther. 2004;27(3):170-9. https://doi.org/10.1016/.j.mpt.2003.12.021.

24. Glaves J. The use of radiological guidelines to achieve a sustained reduction in the number of radiographic examinations of the cervical spine, lumbar spine and knees performed for GPs. Clin Radiol. 2005;60(8):914-20. https:// doi.org/10.1016/j.crad.2005.02.013.

25. Cleland JA, Fritz JM, Brennan GP, Magel J. Does continuing education improve physical therapists' effectiveness in treating neck pain? A randomized clinical trial. Phys Ther. 2009;89(1):38-47. https://doi.org/10. 2522/ptj.20080033.

26. Lineker SC, Bell MJ, Badley EM. Evaluation of an inter-professional educational intervention to improve the use of arthritis best practices in primary care. J Rheumatol. 2011;38(5):931-7. https://doi.org/10.3899/ jrheum.101007.

27. Motor Accidents Authority. Guidelines for the management of whiplash associated disorders. Sydney: State Insurance Regulatory Authority; 2001 Accessed in: https://www.sira.nsw.gov.au/.

28. Motor Accidents Authority. Guidelines for the management of whiplash associated disorders for health professionals. 2nd ed. Sydney: State Insurance Regulatory Authority; 2007. Accessed in https://www.sira.nsw. gov.au/.

29. State Insurance Regulatory Authority. Guidelines for the management of acute whiplash-associated disorders - for health professionals. 3rd ed. Sydney: State Insurance Regulatory Authority; 2014. Accessed in: https:// www.sira.nsw.gov.au/resources-library/motor-accident-resources/ publications/for-professionals/whiplash-resources/SIRA08104-WhiplashGuidelines-1117-396479.pdf

30. Kamper SJ, Rebbeck TJ, Maher CG, McAuley JH, Sterling M. Course and prognostic factors of whiplash: a systematic review and meta-analysis. Pain. 2008;138(3):617-29. https://doi.org/10.1016/j.pain.2008.02.019.

31. Connelly LB, Supangan R. The economic costs of road traffic crashes: Australia, states and territories. Accid Anal Prev. 2006;38(6):1087-93. https:// doi.org/10.1016/j.aap.2006.04.015.

32. Rebbeck T, Sterling M. New whiplash guidelines for physiotherapists. In: Motion. Victoria: Australian Physiotherapy Association; 2016. Accessed in: https://www.sira.nsw.gov.au/resources-library/motor-accident-resources/ publications/for-professionals/whiplash-resources/apa-whiplash-article.

33. Willcock S. Whiplash: facts at your fingertips. Medical Observer. Australia: Australian Doctor Group; 2015. Accessed in: https://www.sira.nsw.gov.au/ resources-library/motor-accident-resources/publications/for-professionals/ whiplash-resources/whiplash-facts

34. Rebbeck TJ, Refshauge KM, Maher CG. Use of clinical guidelines for whiplash by insurers. Aust Health Rev. 2006;30(4):442-9. [published Online First: 2006/11/01]

35. Rebbeck T, Maher CG, Refshauge KM. Evaluating two implementation strategies for whiplash guidelines in physiotherapy: a cluster randomised trial. Aust J Physiother. 2006;52(3):165-74.

36. Rebbeck T, Macedo LG, Maher CG. Compliance with clinical guidelines for whiplash improved with a targeted implementation strategy: a prospective cohort study. BMC Health Serv Res. 2013;13:213. https://doi.org/10.1186/ 1472-6963-13-213. [published Online First: 2013/06/14]

37. Rebbeck T, Macedo L, Paul P, Trevena L, Cameron ID. General practitioners' knowledge of whiplash guidelines improved with online education. Aust Health Rev. 2013;37(5):688-94. https://doi.org/10.1071/ah13057. [published Online First: 2013/10/29]

38. Dey P, Simpson CW, Collins SI, Hodgson G, Dowrick CF, Simison AJ, et al. Implementation of RCGP guidelines for acute low back pain: a cluster randomised controlled trial. Br J Gen Pract. 2004;54(498):33-7.

39. Bekkering GE, Hendriks HJ, van Tulder MW, Knol DL, Hoeijenbos M, Oostendorp RA, et al. Effect on the process of care of an active strategy to implement clinical guidelines on physiotherapy for low back pain: a cluster randomised controlled trial. Qual Saf Health Care. 2005;14(2):107-12. https:// doi.org/10.1136/qshc.2003.009357.

40. Engers AJ, Wensing M, van Tulder MW, Timmermans A, Oostendorp RA, Koes BW, et al. Implementation of the Dutch low back pain guideline for general practitioners: a cluster randomized controlled trial. Spine (Phila Pa 1976). 2005;30(6):559-600.

41. McKee M. Routine data: a resource for clinical audit? Qual Health Care. 1993; 2(2):104-11. [published Online First: 1993/05/08]
42. Herbert R, Jamtvedt G, Hagen KB, Mead J. Am I on the right track? In: Herbert R, Jamtvedt G, Hagen KB, Mead J, editors. Practical Evidence-Based Physiotherapy. 2nd ed. Edinburgh: Elsevier Churchill Livingstone; 2011. p. 161-8.

43. Brook RH, McGlynn EA, Cleary PD. Quality of health care. Part 2: measuring quality of care. N Engl J Med. 1996;335(13):966-70.

44. Cassidy JD, Carroll LJ, Cote P, Lemstra M, Berglund A, Nygren A. Effect of eliminating compensation for pain and suffering on the outcome of insurance claims for whiplash injury. N Engl J Med. 2000;342(16):1179-86. https://doi.org/10.1056/nejm200004203421606. [published Online First: 2000/04/20]

45. Harris IA, Murgatroyd DF, Cameron ID, Young JM, Solomon MJ. The effect of compensation on health care utilisation in a trauma cohort. Med J Aust. 2009;190(11):619-22. [published Online First: 2009/06/03]

46. Casey PP, Feyer AM, Cameron ID. Associations with duration of compensation following whiplash sustained in a motor vehicle crash. Injury. 2015;46(9):1848-55. https://doi.org/10.1016/j.injury.2015.06.018. [published Online First: 2015/07/02]

47. Motor Accidents Authority. A therapist's guide to providing treatment in the NSW motor accidents scheme 2014. Sydney: State Insurance Regulatory; 2014.

48. Motor Accidents Authority. A provider's guide to decisions on reasonable and necessary treatment, rehabilitation, and attendant care. Sydney: State Insurance Regulatory; 2002.

49. Motor Accidents Authority. A therapist's guide to providing treatment in the NSW motor accidents scheme 2014. Sydney: Motor Accidents Authority; 2014.

50. Vernon H, Mior S. The Neck Disability Index: a study of reliability and validity. J Manipulative Physiol Ther. 1991;14(7):409-15. [published Online First: 1991/09/01]

51. Horowitz M, Wilner N, Alvarez W. Impact of event scale: a measure of subjective stress. Psychosom Med. 1979;41(3):209-18.

52. Cohen JW. Statistical power analysis for the behavioral sciences. 2nd ed. Hillside: Lawrence Erlbaum Associates; 1988.

53. Linton SJ, Hallden K. Can we screen for problematic back pain? A screening questionnaire for predicting outcome in acute and subacute back pain Clin J Pain. 1998;14(3):209-15. [published Online First: 1998/10/03]

54. Berecki-Gisolf J, Collie A, McClure R. Reduction in health service use for whiplash injury after motor vehicle accidents in 2000-2009: results from a defined population. J Rehabil Med. 2013;45(10):1034-41. https://doi.org/10. 2340/16501977-1206. [published Online First: 2013/08/27]

55. Stiell IG, Clement CM, Grimshaw J, Brison RJ, Rowe BH, Schull MJ, et al. Implementation of the Canadian C-spine rule: prospective 12 Centre cluster randomised trial. BMJ. 2009;339 https://doi.org/10.1136/bmj.b4146.

56. Johnson MJ, Higlett M, Walsh J, Feyer AM, Cameron ID, Rebbeck T. Whiplash claimants health outcomes and cost pre and post the 1999 NSW CTP legislative reforms. Sydney: Institute of Actuaries of Australia; 2007.

57. Di lorio D, Henley E, Doughty A. A survey of primary care physician practice patterns and adherence to acute low back problem guidelines. Arch Fam Med. 2000;9(10):1015-21. [published Online First: 2000/12/15]

58. Williams CM, Maher CG, Hancock MJ, McAuley JH, McLachlan AJ, Britt H, et al. Low back pain and best practice care: a survey of general practice physicians. Arch Intern Med. 2010;170(3):271-7. https://doi.org/10.1001/ archinternmed.2009.507.

59. Pettersson K, Hildingsson C, Toolanen G, Fagerlund M, Bjornebrink J. MRI and neurology in acute whiplash trauma. No correlation in prospective examination of 39 cases. Acta Orthop Scand. 1994;65(5):525-8. [published Online First: 1994/10/01]

60. Ronnen HR, PJd K, Brink PR, van der Bijl HJ, Tonino AJ, Franke CL. Acute whiplash injury: is there a role for MR imaging?--a prospective study of 100 patients. Radiology. 1996;201(1):93-6. https://doi.org/10.1148/radiology.201. 1.8816527.

61. Voyvodic F, Dolinis J, Moore VM, Ryan GA, Slavotinek JP, Whyte AM, et al. MRI of car occupants with whiplash injury. Neuroradiology. 1997;39(1): 35-40. https://doi.org/10.1007/s002340050363.

62. Hendriks EJ, Scholten-Peeters GG, van der Windt DA, Neeleman-van der Steen CW, Oostendorp RA, Verhagen AP. Prognostic factors for poor recovery in acute whiplash patients. Pain. 2005:114(3):408-16.

63. Kongsted A, Sorensen JS, Andersen H, Keseler B, Jensen TS, Bendix T. Are early MRI findings correlated with long-lasting symptoms following whiplash injury? A prospective trial with 1-year follow-up. Eur Spine J. 2008; 17(8):996-1005. https://doi.org/10.1007/s00586-008-0687-9. [published Online First: 2008/05/31] 
64. Vetti N, Krakenes J, Eide GE, Rorvik J, Gilhus NE, Espeland A. Are MRI highsignal changes of alar and transverse ligaments in acute whiplash injury related to outcome? BMC Musculoskelet Disord. 2010;11:260. https://doi.org/ 10.1186/1471-2474-11-260. [published Online First: 2010/11/13]

65. Deyo RA. Real help and red herrings in spinal imaging. N Engl J Med. 2013; 368(11):1056-8. https://doi.org/10.1056/NEJMe1215599.

66. Lurie JD, Birkmeyer NJ, Weinstein JN. Rates of advanced spinal imaging and spine surgery. Spine. 2003;28(6):616-20. https://doi.org/10.1097/01.brs. 0000049927.37696.dc. [published Online First: 2003/03/19]

67. Webster BS, Cifuentes M. Relationship of early magnetic resonance imaging for work-related acute low back pain with disability and medical utilization outcomes. J Occup Environ Med. 2010;52(9):900-7. https://doi.org/10.1097/ JOM.0b013e3181ef7e53.

68. Flynn TW, Smith B, Chou R. Appropriate use of diagnostic imaging in low back pain: a reminder that unnecessary imaging may do as much harm as good. J Orthop Sports Phys Ther. 2011;41(11):838-46. https://doi.org/10. 2519/jospt.2011.3618. [published Online First: 2011/06/07]

69. Smith-Bindman R, Miglioretti DL, Johnson E, Lee C, Feigelson HS, Flynn M, et al. Use of diagnostic imaging studies and associated radiation exposure for patients enrolled in large integrated health care systems, 1996-2010. JAMA. 2012;307(22):2400-9. https://doi.org/10.1001/jama.2012.5960.

70. Carlesso L, Bartlett DJ, Padfield B, Chesworth BM. Cervical manipulation and informed consent: Canadian manipulative physiotherapists opinions on communicating risk. Physiother Can. 2007 59. https://doi.org/10.3138/ptc.59. 2.86 .

71. Corkery MB, Edgar KL, Smith CE. A survey of physical therapists' clinical practice patterns and adherence to clinical guidelines in the management of patients with whiplash associated disorders (WAD). J Man Manip Ther. 2014;22(2):75-89. https://doi.org/10.1179/2042618613Y.0000000048.

72. Scholten-Peeters GG, Bekkering GE, Verhagen AP, van Der Windt DA, Lanser K, Hendriks EJ, et al. Clinical practice guideline for the physiotherapy of patients with whiplash-associated disorders. Spine. 2002;27(4):412-22. [published Online First: 2002/02/13]

73. Moore A, Jackson A, Jordan J, Hammersley S, Hill J, Mercer C, et al. Clinical guidelines for the physiotherapy management of whiplash associated disorder. London: Chartered Society of Physiotherapy; 2005.

74. TRACsa. Trauma and Injury Recovery. Clinical guidelines for best practice management of acute and chronic whiplash-associated disorders. Adelaide: TRACsa: Trauma and Injury Recovery; 2008.

75. Carroll $L$, Cassidy JD, Cote P. The role of pain coping strategies in prognosis after whiplash injury: passive coping predicts slowed recovery. Pain. 2006;124(1-2):18-26. https://doi.org/10.1016/j.pain.2006.03.012. [published Online First: 2006/04/29]

76. Carroll L, Holm L, Hogg-Johnson S, Cote P, Cassidy JD, Haldeman S, et al. Course and prognostic factors for neck pain in whiplash-associated disorders (WAD): results of the Bone and Joint Decade 2000-2010 Task Force on Neck Pain and Its Associated Disorders. Spine (Phila Pa 1976). 2008;33(Supp 4):S83-92. https://doi.org/10.1097/BRS.0b013e3181643eb8.

77. Rebbeck T, Sindhusake D, Cameron ID, Rubin G, Feyer AM, Walsh J, et al. A prospective cohort study of health outcomes following whiplash associated disorders in an Australian population. Inj Prev. 2006;12(2):93-8. https://doi. org/10.1136/ip.2005.010421.

78. Sterling M, Hendrikz J, Kenardy J. Compensation claim lodgement and health outcome developmental trajectories following whiplash injury: A prospective study. Pain. 2010;150(1):22-8. https://doi.org/10.1016/j.pain.2010. 02.013. [published Online First: 2010/03/24]

79. Ritchie C, Sterling M. Recovery Pathways and Prognosis After Whiplash Injury. J Orthop Sports Phys Ther, 46. 2016;(10):851-61. https://doi.org/10. 2519/jospt.2016.6918. [published Online First: 2016/09/07]

80. King MA, Roberts MS. The influence of the pharmaceutical benefits scheme (PBS) on inappropriate prescribing in Australian nursing homes. Pharm World Sci. 2007;29(1):39. https://doi.org/10.1007/s11096-005-5618-9.

81. Green CJ, Maclure M, Fortin PM, Ramsay CR, Aaserud M, Bardal S. Pharmaceutical policies: effects of restrictions on reimbursement. Cochrane Database Syst Rev. 2010;8:CD008654. https://doi.org/10.1002/14651858. CD008654.

82. Ritchie C, Hendrikz J, Kenardy J, Sterling M. Derivation of a clinical prediction rule to identify both chronic moderate/severe disability and full recovery following whiplash injury. Pain. 2013;154(10):2198-206. https://doi. org/10.1016/j.pain.2013.07.001. [published Online First: 2013/07/09]
83. Ritchie C, Hendrikz J, Jull G, Elliott J, Sterling M. External validation of a clinical prediction rule to predict full recovery and ongoing moderate/ severe disability following acute whiplash injury. J Orthop Sports Phys Ther. 2015;45(4):242-50. https://doi.org/10.2519/jospt.2015.5642. [published Online First: 2015/04/02]

84. Kerr D, Bradshaw L, Kelly AM. Implementation of the Canadian C-spine rule reduces cervical spine $\mathrm{x}$-ray rate for alert patients with potential neck injury. J Emer Med. 2005;28(2):127-31. https://doi.org/10.1016/j. jemermed.2004.08.016.

85. Nicholas M. For better return to work outcomes, knowledge is not enough: Lessons from an early intervention trial. In: Recovery at work: A new way of thinking about work injuries. Global Access Partners. 2016. http://www. globalaccesspartners.org/Recovery_at_Work_GAP_Strategic_Roundtable_ Report_May2016.pdf. Accessed 21 Jul 2017.

86. Bandong AN, Leaver A, Mackey M, Sterling M, Kelly J, Ritchie C, et al. Referral to specialist physiotherapists in the management of whiplash associated disorders: perspectives of healthcare practitioners. Musculoskelet Sci Pract. 2017;34:14-26. https://doi.org/10.1016/j.msksp.2017.11.006.

87. Akbari A, Mayhew A, Al-Alawi MA, Grimshaw J, Winkens R, Glidewell E, et al. Interventions to improve outpatient referrals from primary care to secondary care. Cochrane Database Syst Rev. 2008:4:Cd005471. https://doi. org/10.1002/14651858.CD005471.pub2. [published Online First: 2008/10/10]

88. Wåhlberg $H$, Valle PC, Malm S, Broderstad AR. Impact of referral templates on the quality of referrals from primary to secondary care: a cluster randomised trial. BMC Health Serv Res. 2015;15(1):353. https://doi.org/10. 1186/s12913-015-1017-7.

89. Stratford PW, Gill C, Westaway MD, Binkley J. Assessing disability and change on individual patients: a report of a patient specific measure. Physiother Can. 1995 47. doi: https://doi.org/10.3138/ptc.47.4.258.

90. Lovibond SH, Lovibond PF. Manual for the depression anxiety stress scales (DASS). Psychology Foundation: Sydney; 1995.

91. Jordan A, Manniche C, Mosdal C, Hindsberger C. The Copenhagen Neck Functional Disability Scale: a study of reliability and validity. J Manipulative Physiol Ther. 1998;21(8):520-7. [published Online First: 1998/11/03]

92. Pinfold M, Niere KR, O'Leary EF, Hoving JL, Green S, Buchbinder R. Validity and internal consistency of a whiplash-specific disability measure. Spine. 2004;29(3):263-8. [published Online First: 2004/01/31]

93. Roland M, Fairbank J. The Roland-Morris disability questionnaire and the Oswestry disability questionnaire. Spine. 2000;25(24):3115-24

94. Feise RJ, Menke MJ. Functional rating index: a new valid and reliable instrument to measure the magnitude of clinical change in spinal conditions. Spine. 2001;26(1):78-87.
Ready to submit your research? Choose BMC and benefit from:
- fast, convenient online submission
- thorough peer review by experienced researchers in your field
- rapid publication on acceptance
- support for research data, including large and complex data types
- gold Open Access which fosters wider collaboration and increased citations
- maximum visibility for your research: over $100 \mathrm{M}$ website views per year
At BMC, research is always in progress.
Learn more biomedcentral.com/submissions 